\title{
Challenges of motherhood in adolescent girls
}

\author{
Mohini Rajoriya, Ruchi Kalra* \\ Department of Obstetrics \& Gynaecology, People's College of Medical Sciences \& Research Centre, Bhopal, Madhya \\ Pradesh, India
}

Received: 19 March 2015; Revised: 22 March 2015

Accepted: 19 April 2015

\section{*Correspondence:}

Dr. Ruchi Kalra,

E-mail: drruchi.kalra15@gmail.com

Copyright: (C) the author(s), publisher and licensee Medip Academy. This is an open-access article distributed under the terms of the Creative Commons Attribution Non-Commercial License, which permits unrestricted non-commercial use, distribution, and reproduction in any medium, provided the original work is properly cited.

\begin{abstract}
Background: National Family Health Survey (NFHS)-3 revealed that 16\% of women, aged 15-19 years, have already started childbearing of them urban were $8.7 \%$ and rural were $19.1 \%$. Teenage pregnancy is of serious concern because maternal age plays a significant role in adverse outcome and complications of pregnancy. The study was done to find out incidence and analyse the maternal, foetal outcome in adolescent pregnancy.

Methods: The study was conducted at People's College of Medical Sciences and Research Centre, Bhopal from January 2010 to July 2013. All cases of teenage pregnancy who delivered during study period were analysed for age distribution, mode of delivery, indications for caesarean section, complications and neonatal weight.

Results: 78 adolescent girls delivered during study period which was $2.1 \%$ of total deliveries. $78 \%$ were of age group 19 years, $18 \%$ of cases were of 18 years of age $2.5 \%$ cases were of 17 years and $1.28 \%$ of case 14 years. $90 \%$ were primigravida. Total pre-term deliveries were $13 \%$ of the all adolescent deliveries. $46 \%$ delivered by caesarean section. Majority of caesarean sections were done for cephalo-pelvic disproportion (50\% cases) followed by foetal distress (22\%). $52 \%$ of cases had baby weight more than $2.5 \mathrm{~kg}$. $35 \%$ of cases had weight between $2 \mathrm{~kg}$ and $2.5 \mathrm{~kg}$ and $13 \%$ of cases had weight less than $2 \mathrm{~kg}$. PIH was found in 32\% of cases, Anaemia and IUGR was present in $29 \%$ of cases. PPH occurred in $12.80 \%$ cases.

Conclusions: In teenage pregnancy cesarean section rate was high (46\%). PIH, anemia and IUGR were the associated complications. So we should best aim to reduce the incidence of teenage pregnancy, not only to minimize the adverse outcomes on young mothers but also to limit the family-size by providing adolescent friendly health services.
\end{abstract}

Keywords: Teenage pregnancy, Adolescent friendly health services

\section{INTRODUCTION}

There are 16 million adolescent girl's world over of which two million girls are under the age of 15 who give birth every year - most in low- and middle-income countries. Worldwide, one in five girls has given birth by the age of 18. Almost all adolescent births - about 95\% occur in low- and middle-income countries. Adolescents account for $13 \%$ of maternal deaths. Stillbirths and newborn deaths are $50 \%$ higher among infants of adolescent mothers than among infants of women aged 20-29 years. Teenage girls are twice as likely as women over 20 to die of complications from pregnancy and childbirth. Girls under the age of 15 are five times as likely as women in their twenties to die of these complications. Teen pregnancy in India is high with 62 pregnant teens out of every 1000 women ( State of the World Population 2008, UNFPA) 4\% of women aged 1519 were reported to be currently pregnant with their first child. ${ }^{1}$

Data of the National Family Health Survey (NFHS)-3 revealed that $16 \%$ of women, aged 15-19 years, have already started childbearing of them urban were $8.7 \%$ and rural were $19.1 \%$. $^{2}$ This proportion is highest in the state of Bihar (46\%), followed by West Bengal (41\%), Rajasthan (41\%) and Jharkhand (36\%). ${ }^{3}$ 
Teenage pregnancy is of serious concern because maternal age plays a significant role in adverse outcome and complications of pregnancy. Teenage pregnancies represent a high-risk group in reproductive terms because of the double burden of reproduction and growth. Complications of pregnancy and childbirth are the leading cause of mortality among girls aged 15-19 years in developing countries. ${ }^{4,5}$ The teenage pregnancy is considered as high risk pregnancy .They are three times more at risk of developing anaemia, pre-term labour and two times more chance of developing Pregnancy induced hypertension and its related complications. ${ }^{6}$

\section{Aim \& objectives}

The study was done to find out incidence and analyse the maternal, foetal outcome in adolescent pregnancy at our institute.

\section{METHODS}

The study was conducted at People's College of Medical Sciences and Research Centre, Bhopal from January 2010 to July 2013. Teenage pregnancy was defined as pregnancy occurring during the maternal ages of 13-19 years at delivery. All cases of Teenage Pregnancy in this age group who delivered during study period were included in the present study. Their age distribution, mode of delivery, indications for caesarean section and neonatal weight was studied. It was a retrospective record based cross sectional observational study.

\section{RESULTS}

Total deliveries during study period were 3641 deliveries. During this period 78 adolescent girls delivered which was $2.1 \%$ of total deliveries.

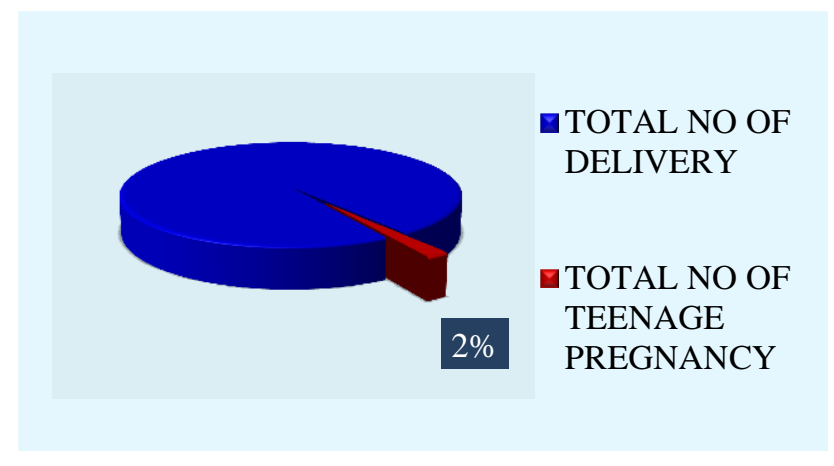

Figure 1: Total \% of adolescent pregnancy.

Upon studying the age distribution maximum number of cases $78 \%$ were of 19 years were of age group 19 years, $18 \%$ of cases were of 18 years of age $2.5 \%$ cases were of 17 years and $1.28 \%$ of case 14 years were found. $Z$ test of proportion was applied and $\mathrm{P}$ value was significant $(<0.05)$.

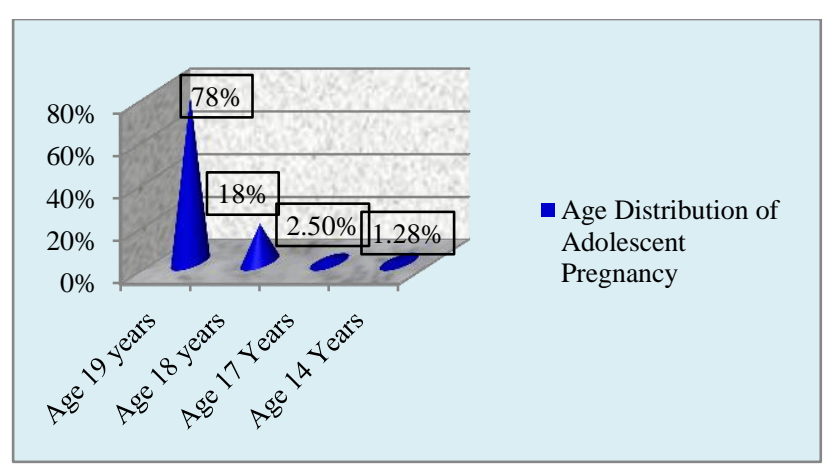

Figure 2: Age distribution of adolescent pregnancies.

Maximum number of cases were primigravida which were $90 \%$ of total adolescent deliveries rest $9 \%$ cases were second gravida and $1 \%$ case was third gravida. $\mathrm{Z}$ test of proportion was applied and $\mathrm{P}$ value was significant $(<0.05)$.

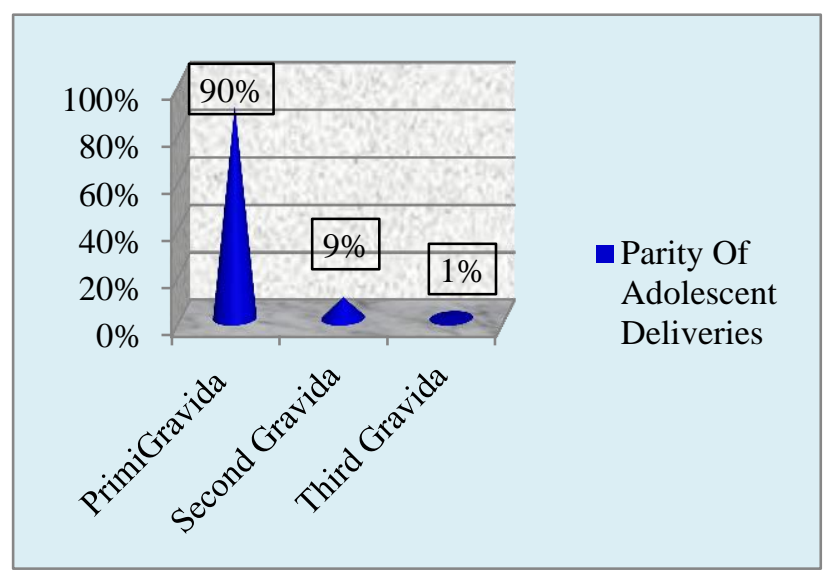

Figure 3: Parity status of adolescent deliveries.

Of the 78 teenage mothers $46 \%$ delivered by caesarean section and $54 \%$ of the cases delivered vaginally. $\mathrm{Z}$ test of proportion was applied and $\mathrm{P}$ value was insignificant $(>0.05) 87 \%$ cases were term deliveries and $13 \%$ of the cases were pre-term. $\mathrm{Z}$ test of proportion was applied and $\mathrm{P}$ value was significant $(<0.05)$.

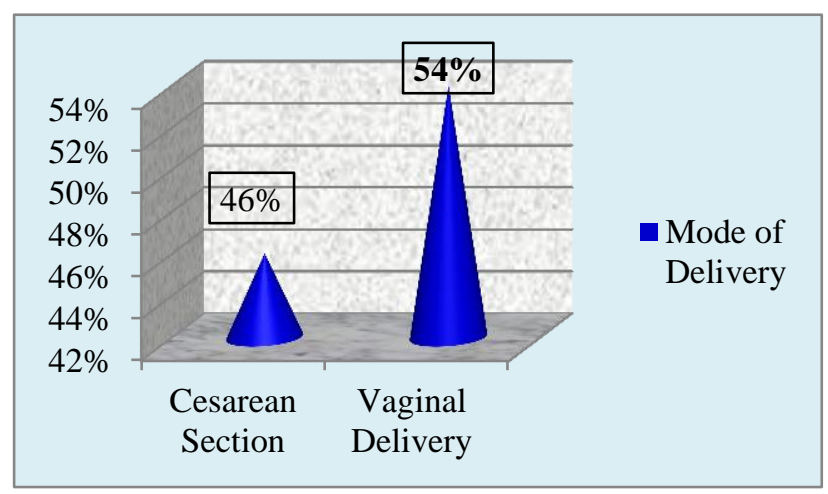

Figure 4: Mode of delivery. 


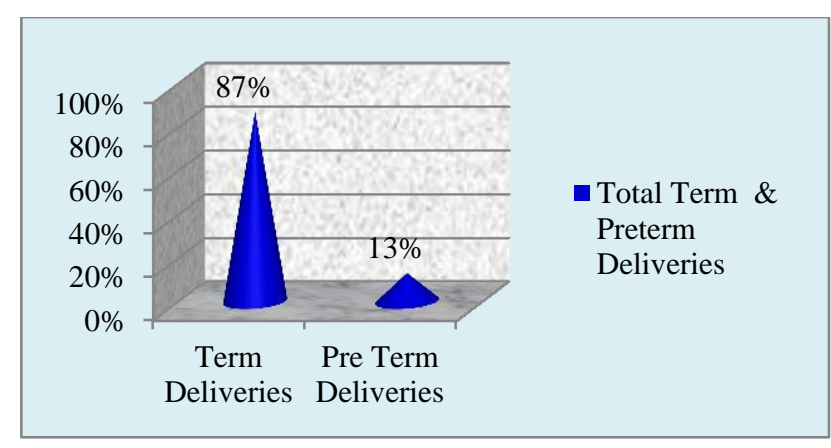

Figure 5: Term \& preterm deliveries.

Total number of adolescent who delivered by caesarean section were $46 \%$ (36 cases) of the total adolescent deliveries. Indications for the caesarean sections were also studied. Majority of caesarean sections were done for cephalo-pelvic disproportion ( $50 \%$ cases) followed by foetal distress in $22 \%$ cases, oligohydramnios in $8 \%$ of cases, obstructed labour and breech in $6 \%$ cases. Other indications were PROM $(2.7 \%)$, preeclampsia $(2.7 \%)$ and ante partum haemorrhage $(2.7 \%)$. Applying $\mathrm{Z}$ test of proportion results were statistically significant $(\mathrm{P}<0.05)$.

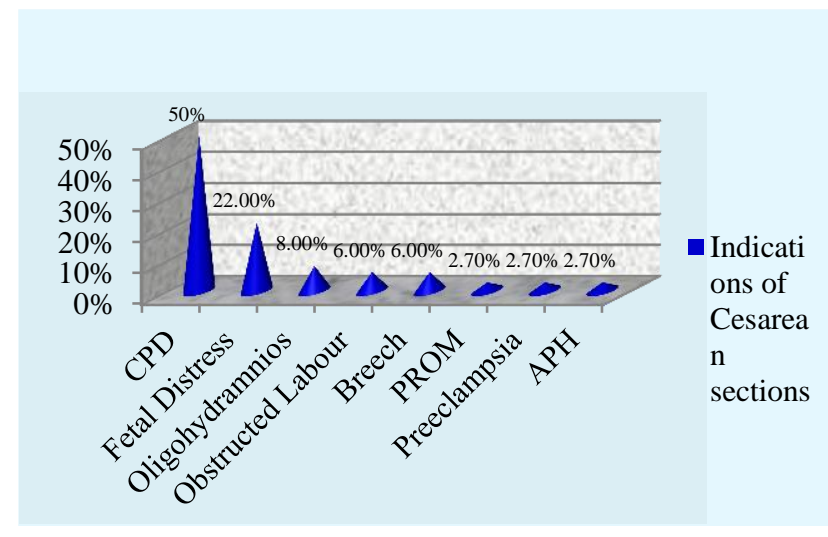

Figure 6: Indications of cesarean sections.

$52 \%$ of cases had baby weight more than $2.5 \mathrm{~kg}$. $35 \%$ of cases had weight between $2 \mathrm{~kg}$ and $2.5 \mathrm{~kg}$ and $13 \%$ of cases had weight less than $2 \mathrm{~kg}$. So total $48 \%$ cases were in category of low birth weight. $\mathrm{Z}$ test of proportion results were not statistically significant $(P>0.05)$.

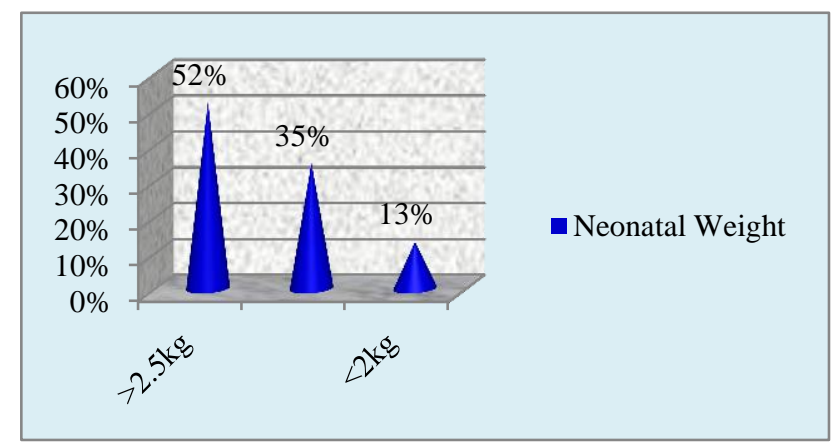

Figure 7: Neonatal weight.
The complications that were associated with adolescent pregnancy were noted. PIH was found in $32 \%$ of cases, Anaemia and IUGR was present in $29 \%$ in each. PPH occurred in $12.80 \%$ cases.

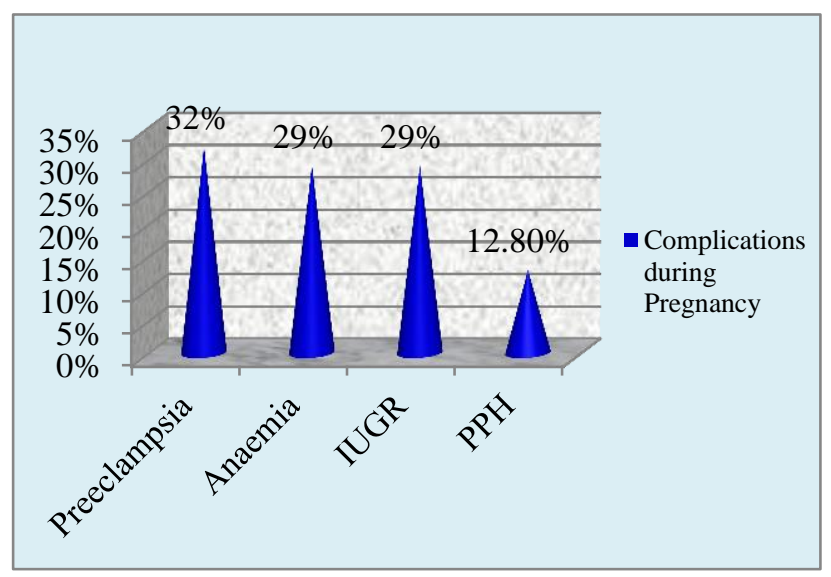

Figure 8: Associated complications during pregnancy.

\section{DISCUSSION}

Although the legal age at marriage is 18 years for females and 21 years for males in India, early marriage is common. By the age of 15 years, $26 \%$ of females are married, and by the age of 18 years, this figure rises to $54 \%$. Most reproduction in India occurs within marriage; so, the low age at marriage automatically links to early onset of sexual activity and thereby fertility. ${ }^{7,8}$ In our study incidence was $2 \%$ where as in Yasmin and coworkers study the incidences of teenage pregnancy was found to be $5.1 \%$. NHFS 3 has reported the incidence as $16 \%$. In our study caesarean section rate was high, $46 \%$ as compared to $11.6 \%$ in Yasmin and co-workers study and in Mukhopadhyay et al. study was $28.3 \%$. In our study highest incidence for the indication of caesarean section was cephalo pelvic disproportion and foetal distress. In Yasmin et al. study highest incidence was of foetal distress followed by mal presentation and then contracted pelvis. $^{9}$ In another study by Mukhopadhyay and co-workers reported in their study highest indication as foetal distress followed by cephalo pelvic disproportion. ${ }^{10}$ As anatomical development is still occurring in adolescent girl cephalo pelvic disproportion can result. Complications associated with adolescent deliveries were Pre eclampsia (32\%) anaemia (29\%), IUGR (29\%), PPH (12.8\%). The limitation of our study was that we did not compare these results with adult deliveries but in a study done in Nigeria reported that these complications were higher than in older population ${ }^{11}$ Mahavarkar and co-workers in their study in Maharashtra reported that the teenage mothers were nearly three times more at risk of developing anaemia, twice as likely to develop hypertensive problems in pregnancy. In our study neonatal weight less than $2.5 \mathrm{~kg}$ was in $48 \%$ of neonates which was high as compared to study by Mukhopadhyay where it was $39.8 \%$. 
India as a developing nation has to especially address adolescent health as major health priority. Both the social awareness and political will is needed to tackle the health problem of teenage pregnancy

WHO Guidelines ${ }^{12}$ as stated below on preventing early pregnancy and poor reproductive outcomes amongst adolescents in developing countries has recommended.

\section{Reduce marriage before the age of 18 years}

Encourage political leaders, planners and community leaders to formulate and enforce laws and policies to prohibit marriage of girls before 18 years of age. Undertake interventions to delay marriage of girls until 18 years of age by influencing family and community norms. These interventions should be undertaken in conjunction with interventions directed at political leaders/planners.

- Implement interventions to inform and empower girls, in combination with interventions to influence family and community norms, to delay the age of marriage among girls under 18 years of age.

- Increase educational opportunities for girls through formal and non-formal channels, to delay marriage until 18 years of age.

\section{Reduce pregnancy before the age of 20 years}

Advocate for adolescent pregnancy prevention among all stakeholders through interventions such as: information provision, sexuality and health education, life skills building, contraceptive counselling and service provision, and the creation of supportive environments.

- Maintain and improve efforts to retain girls in school, both at the primary and secondary levels.

- Offer interventions that combine curriculum-based sexuality education with contraceptive promotion to adolescents, in order to reduce pregnancy rates.

- Offer and promote postpartum and post-abortion contraception to adolescents through multiple home visits and/or clinic visits to reduce the chances of second.

\section{Increase use of contraception by adolescents at risk of unintended pregnancy}

Undertake efforts with political leaders and planners to formulate laws and policies to increase adolescent access to contraceptive information and services, including emergency contraceptives.

- Undertake interventions to influence community members to support access to contraceptives for adolescents.

- Implement interventions to improve health service delivery to adolescents as a means of facilitating their access to and use of contraceptive information and services.

- Implement interventions at scale that provide accurate information and education about contraceptives, in particular curriculum-based sexuality education (CBSE), to increase contraceptive use among adolescents.

- Conditional recommendation:

- Implement interventions to reduce the financial cost of contraceptives to adolescents.

\section{Reduce coerced sex among adolescents}

Continue efforts with political leaders, planners and the community to formulate laws and policies that punish perpetrators of coerced sex involving adolescent girls, to enforce these laws and policies in a way that empowers victims and their families, and to monitor their enforcement.

- Implement interventions to enhance adolescent girls' abilities to resist coerced sex and to obtain support if they experience coerced sex by:

- Building their self-esteem;

- Developing their life skills in areas such as communication and negotiation; and

- Improving their links to social networks and their ability to obtain social support.

- The above interventions should be combined with interventions to create supportive social norms that do not condone coerced sex.

- Implement interventions to engage men and boys to critically assess gender norms and normative behaviours (e.g. gender transformative approaches) that relate to sexual coercion and violence. Combine these with wider interventions to influence.

\section{Reduce unsafe abortion among adolescents}

Ensure that laws and policies enable adolescents to obtain safe abortion services.

- Enable adolescents to obtain safe abortion services by informing them and other stakeholders about:

- The dangers of unsafe methods of interrupting a pregnancy;

- The Safe abortion services that are legally available; and

- Where and under what circumstances these services can be obtained legally.

- Identify and overcome barriers to the provision of safe abortion services to adolescents.

- $\quad$ Ensure access to post-abortion by adolescents care as a life-saving medical intervention, whether or not the abortion or attempted abortion was legal.

- Ensure that adolescents who have had abortions can obtain post-abortion contraceptive information and services, whether or not the abortion was legal. 


\section{Increase use of skilled antenatal, childbirth and postnatal care among adolescents}

Provide information to all pregnant adolescents and other stakeholders about the importance of utilizing skilled antenatal care.

- $\quad$ Provide information to all pregnant adolescents and other stakeholders about the importance of utilizing skilled childbirth care.

- Promote birth and emergency preparedness in antenatal care strategies for pregnant adolescents (in household, community and health facility settings).

- Expand the availability and access to basic emergency obstetric care (BEmOC) and comprehensive emergency obstetric care (CEmOC) to all populations, including.

\section{CONCLUSIONS}

In present study teenage pregnancies had high caesarean section due to CPD and foetal distress. Also occurrence of pregnancy related complications (PIH, IUGR, anaemia, PPH) were high. Therefore it is recommended that Teenage Pregnancy be best prevented. To address this multifaceted problem, we should aim to reduce the incidence of teenage pregnancy, not only to minimize the adverse outcomes on young mothers but also to limit the family-size. Efforts need to be directed towards strict enforcement of laws prohibiting teenage marriage in India. Effective intervention to prevent teenage marriages is an area of research which requires further community based exploration. However, antenatal health visits of these teen pregnant girls can be utilized as an opportunity to educate them about various contraceptives and spacing methods to delay next pregnancy till they mature. All health aspects including psychological and emotional support should be offered to these adolescent pregnant girls besides the routine antenatal care. The counselling and advice should also address the dietary needs which include demand of pregnancy and developmental demands of the body.

Limitations: Study included adolescent girls and the data was not compared with the adult population so relative risk of adolescent pregnancy could not be calculated.

Recommendation for further research: Identify effective interventions and strategies to enforce marriage law to delay the age of marriage by 18years, motivate girls and their parents to enrol them in the school, educate girls about safe sex and use of contraceptives. Involvement of all the stakeholders to promote safe abortions and provide access to adolescent friendly antenatal, delivery and postnatal care.
Funding: No funding sources

Conflict of interest: None declared

Ethical approval: The study was approved by the institutional regulatory body

\section{REFERENCES}

1. WHO Facts Sheet. Adolescent pregnancy, September 2014 Available at: http://www.who.int/mediacentre/factsheets/fs364/en/ . Accessed 9 March 2015.

2. IIPS. National family health survey-3, 2014. Available at: http://www.rchiips.org/nfhs/pdf/India.pdf. Assessed 10 March 2015.

3. Ministry of Health and Family Welfare, Government of India. District level household and facility survey 2007-08, 2009. Available at: http://www.rchiips.org/pdf/india_report_dlhs-3.pdf. Assessed 9 March 2015.

4. Mayor S. Pregnancy and childbirth are leading causes of death in teenage girls in developing countries. BMJ. 2004;328:1152.

5. Agarwal N, Reddaiah VP. Factors affecting birth weight in a suburban community. Health Popul Perspect Issue. 2005;28:189-96.

6. Mahavarkar SH, Madhu CK, Mule VD. A comparative study of teenage pregnancy. J Obstet Gynaecol. 2008 Aug;28(6):604-7.

7. World Health Organization. Towards adulthood: exploring the sexual and reproductive health of adolescents in South Asia. In: WHO, eds. WHO Report. Geneva: World Health Organization; 2003: 244.

8. World Health Organization. Adolescent pregnancy: issues in adolescent health and development. In: WHO, eds. WHO Report. Geneva: World Health Organization; 2004: 86.

9. Yasmin G, Kumar A, Prihar B. Maternal and fetal outcome of teenage pregnancy. Int J Sci Study. 2014 March;1:10-3.

10. Prianka Mukhopadhyay, R. N. Chaudhuri, Bhaskar Paul. Hospital-based perinatal outcomes and complications in teenage pregnancy in India. $\mathbf{J}$ Health Popul Nutr. 2010 Oct;28(5):494-500.

11. Ibrahim Isa Ayuba, Owoeye Gani. Outcome of teenage pregnancy in the Niger Delta of Nigeria. Ethiop J Health Sci. 2012 March;22(1):45-50.

12. World Health Organization. WHO guidelines on lines preventing early pregnancy and poor reproductive outcomes adolescents in developing countries, 2011. Available at: http://www.who.int/maternal_child_adolescent/docu ments/preventing_early_pregnancyen/. Assessed 6 March 2015.

DOI: $10.18203 / 2320-1770 . i j r \operatorname{cog} 20150076$

Cite this article as: Rajoriya M, Kalra R. Challenges of motherhood in adolescent girls. Int J Reprod Contracept Obstet Gynecol 2015;4:696-700. 